\title{
Challenges in sharing of geospatial data by data custodians in South Africa
}

\author{
Sissiel E Kay ${ }^{\mathrm{a}}$ \\ ${ }^{a}$ Chief Directorate: National Geospatial Information, Cape Town, South Africa, Sissiel.kay@drdlr.gov.za
}

\begin{abstract}
As most development planning and rendering of public services happens at a place or in a space, geospatial data is required. This geospatial data is best managed through a spatial data infrastructure, which has as a key objective to share geospatial data. The collection and maintenance of geospatial data is expensive and time consuming and so the principle of 'collect once - use many times' should apply. It is best to obtain the geospatial data from the authoritative source - the appointed data custodian. In South Africa the South African Spatial Data Infrastructure (SASDI) is the means to achieve the requirement for geospatial data sharing. This requires geospatial data sharing to take place between the data custodian and the user. All data custodians are expected to comply with the Spatial Data Infrastructure Act (SDI Act) in terms of geo-spatial data sharing. Currently data custodians are experiencing challenges with regard to the sharing of geospatial data.

This research is based on the current ten data themes selected by the Committee for Spatial Information and the organisations identified as the data custodians for these ten data themes. The objectives are to determine whether the identified data custodians comply with the SDI Act with respect to geospatial data sharing, and if not what are the reasons for this. Through an international comparative assessment it then determines if the compliance with the SDI Act is not too onerous on the data custodians.

The research concludes that there are challenges with geospatial data sharing in South Africa and that the data custodians only partially comply with the SDI Act in terms of geospatial data sharing. However, it is shown that the South African legislation is not too onerous on the data custodians.
\end{abstract}

Keywords: geospatial data, metadata, data custodian, data sharing, legislation, spatial data infrastructure, geospatial dataset, standards, data quality, data acquisition, CSI, SASDI, SDI,

\section{Introduction}

Effective policy formulation and decision making, and the subsequent monitoring and evaluation of these, require relevant information. Now, as most development planning and rendering of public services happens at a place or in a space, it is then geospatial information or data that is mostly required. The geospatial data must be usable by the user in their specific application areas for it to achieve its optimal benefit. For the geospatial data to be usable it must first be accessible from the data supplier, who in turn must have the geospatial data available.

The collection of geospatial data is a time consuming and expensive process and any duplication of geospatial data collection by organisations will be wasteful of scarce resources. It is then better not to duplicate the collection of geospatial data if it is already available. Furthermore, the complex nature of geospatial data usually requires high level of expertise to collect the geospatial data, and such expertise is limited. There are organisations that have the requisite expertise and other resources to collect the required geospatial data. These organisations are collecting the geospatial data routinely as part of their business and can be regarded as reliable sources of the geospatial data. Such geospatial data collected is regarded as authoritative data. These organisations are then regarded as the data custodian for the geospatial data for which they are assigned. The principle of 'collect once use many times' is also regarded as part of sound geospatial data governance. This requires that there is geospatial data sharing taking place between the data custodian and the user (data recipient).

All data custodians are expected to comply with the Spatial Data Infrastructure Act (Act No. 54 of 2003) (SDI Act) in terms of geospatial data sharing. Currently data custodians are experiencing challenges with regard to the sharing of geospatial data.

The Committee for Spatial Information (CSI) is responsible to implement the SDI Act and the National Spatial Information Framework (NSIF) serves as the secretariat for the CSI.

The SDI Act has got various components but this research project will only focus on the sharing of geospatial data.

\section{Significance}

The acquisition of geospatial data and the maintenance of this data in a database are costly and tedious processes. Also, identified geospatial datasets should be supplied by the authoritative source for this data. Yet there is often 
du- plication of effort among organs of State, which is wasteful of resources. It is for these reasons that the sharing of geospatial data is a key objective of a spatial data infrastructure, including the South African Spatial Data Infrastructure (SASDI), in terms of the Spatial Data Infrastructure Act (Act No. 54 of 2003).

It is important then that the authoritative sources or data custodians of the key geospatial datasets have the capacity and the capability to share/supply their geospatial data with users (data recipients).

The challenges and successes of sharing/supplying of geospatial data by data custodians in South Africa plays an significant role for effective use of geospatial data and how geospatial data can be used to make informed decisions for effective governance within the public sector.

The South African legislation guiding the sharing of geospatial data is also critical for the implementation of an effective and efficient SASDI within the country.

By performing this research project it can recommend improvements in data sharing methods for geospatial data through the effective implementation of the Spatial Data Infrastructure Act (SDI Act).

\section{Delineation}

The Committee for Spatial Information (CSI) has identified ten (10) geospatial data themes and only the data custodian identified by the CSI for these ten themes will be evaluated in terms of the geospatial data sharing component of the SDI Act.

Four countries were identified and their legislation with regard to spatial data infrastructure implementation was looked at. The successes and challenges that they experience relating to the sharing of geospatial data were evaluated. These four countries are U.S.A., Algeria, Indonesia and Belgium, and were interviewed during the occasion of the Geospatial World Forum 2016.

\section{Assumptions}

The following assumption has been made with regard to sharing of digital geospatial data:

- All of the data custodians that were identified by the Committee for Spatial Information are aware of their mandate with regard to acquisition, maintenance and sharing of geospatial data.

\section{Equipment}

The research equipment mainly was the use of the PC to prepare the various questionnaires.

The questionnaires were sent out to the identified data custodians via email and follow ups were done via telephone to ensure that a reasonable amount of the ten identified data custodians could respond.

The senior officials from the countries and the Director of NSIF were interviewed as opportunities presented themselves.

\section{Research methodology}

The methodologies for this research were based on various methods to establish why there are challenges with regard to sharing of geospatial data and what implications the South African legislation have on geospatial data sharing. The data gathering occurred in terms of questionnaires and personal interviews with the relevant stakeholders. Five interviews were completed with five senior representatives from four other countries to determine their geospatial data sharing methods and how they implement spatial data infrastructure (SDI) within their respective countries. For the identified data custodians a data custodian questionnaire was prepared and it was emailed to the identified data custodians to be completed. The Director of NSIF was interviewed to assess how South African data custodians comply with geospatial data sharing requirements and what is her view on the legislation within South Africa regarding geospatial data sharing and implementation of SASDI.

\begin{tabular}{|c|c|c|}
\hline $\begin{array}{l}\text { Theme } \\
\text { (Dataset) }\end{array}$ & $\begin{array}{ll}\text { Data } & \\
\text { Cust } \\
\text { odia } \\
\text { n } \\
\text { cont } \\
\text { ribu } \\
\text { ting } \\
\text { to } \\
\text { mai } \\
\text { n } \\
\text { data } \\
\text { set }\end{array}$ & $\begin{array}{l}\text { Identifie } \\
\text { d Data } \\
\text { Custodia } \\
\text { n }\end{array}$ \\
\hline $\begin{array}{l}\text { Administrat } \\
\text { ive } \\
\text { Boundaries } \\
\text { Dataset }\end{array}$ & $\begin{array}{l}\text { Municipal } \\
\text { Demarcation } \\
\text { —Board } \\
\text { Department of } \\
\text { Justice and } \\
\text { Constitutional } \\
\text { Development } \\
\text { (DOJ \&CD) }\end{array}$ & $\begin{array}{c}\text { Municipal } \\
\text { Demarcation } \\
\text { Board }\end{array}$ \\
\hline $\begin{array}{l}\text { Roads } \\
\text { Dataset }\end{array}$ & $\begin{array}{l}\text { CSouth African } \\
\text { National } \\
\text { Roads Agency } \\
\text { —Limited } \\
\text { (SANRAL) } \\
\text { Chief } \\
\text { Directorate } \\
\text { National } \\
\text { Geospatial } \\
\text { Information } \\
\text { (CD: NGI) }\end{array}$ & $\begin{array}{l}\text { Department } \\
\text { of Transport } \\
\text { (DoT) }\end{array}$ \\
\hline
\end{tabular}




\begin{tabular}{|c|c|c|}
\hline $\begin{array}{l}\text { Imagery } \\
\text { Dataset }\end{array}$ & $\begin{array}{l}\text { CSouth African } \\
\text { National } \\
\text { Space Agency } \\
\text { ᄃ(SANSA) } \\
\text { Chief } \\
\text { Directorate } \\
\text { National } \\
\text { Geospatial } \\
\text { Information } \\
\text { (CD: NGI) }\end{array}$ & \begin{tabular}{l}
\multicolumn{1}{c}{ Chief } \\
Directorate \\
National \\
Geospatial \\
Information \\
(CD: NGI)
\end{tabular} \\
\hline \begin{tabular}{l}
\multicolumn{1}{c}{ Social } \\
Statistics \\
(Geographical \\
Place Names) \\
Dataset
\end{tabular} & $\begin{array}{l}\text { Statistics } \\
\text { South Africa } \\
\text { ᄃ(STATSSA) } \\
\text { Chief } \\
\text { Directorate } \\
\text { National } \\
\text { Geospatial } \\
\text { Information } \\
\text { (CD: NGI) } \\
\text { South African } \\
\text { Geographic } \\
\text { Names } \\
\text { Council } \\
\text { (SAGNC) }\end{array}$ & $\begin{array}{c}\text { Statistics } \\
\text { (STATSSA) }\end{array}$ \\
\hline $\begin{array}{l}\text { Land Use } \\
\text { Dataset }\end{array}$ & $\begin{array}{l}\text { Chief } \\
\text { Directorate } \\
\text { National } \\
\text { Geospatial } \\
\text { Information } \\
\text { (CD: NGI) }\end{array}$ & \begin{tabular}{l}
\multicolumn{1}{c}{ Chief } \\
Directorate \\
National \\
Geospatial \\
Information \\
(CD: NGI)
\end{tabular} \\
\hline $\begin{array}{c}\text { Land Cover } \\
\text { Dataset }\end{array}$ & $\begin{array}{l}\text { Chief } \\
\text { Directorate } \\
\text { National } \\
\text { —Geospatial } \\
\text { Information } \\
\text { (CD: NGI) }\end{array}$ & \begin{tabular}{l}
\multicolumn{1}{c}{ Chief } \\
Directorate \\
National \\
Geospatial \\
Information \\
(CD: NGI)
\end{tabular} \\
\hline $\begin{array}{c}\text { Hydrology } \\
\text { Dataset }\end{array}$ & $\begin{array}{l}\text { CDepartment of } \\
\text { Water Affairs } \\
\text { Sanitation } \\
\text { СDWAS) } \\
\text { Catchment } \\
\text { Management } \\
\text { —Agency } \\
\text { (CMA) } \\
\text { Chief } \\
\text { Directorate } \\
\text { National } \\
\text { Geospatial } \\
\text { Information }\end{array}$ & $\begin{array}{l}\text { Department of } \\
\text { Water Affairs } \\
\text { (DWAS) }\end{array}$ \\
\hline
\end{tabular}

\begin{tabular}{|c|l|c|}
\hline & (CD: NGI) & \\
& & \\
& & \\
& & \\
\hline Cadastre & {$[$ Chief } & Chief \\
Dataset & Surveyor & Surveyor \\
& General & General \\
& (CSG) & \\
& Provincial & \\
& Surveyor & \\
& General & \\
\hline Conservation & CDepartment of & Department \\
Areas & Environmenta & of \\
Dataset & 1 Affairs & Environmental \\
& (DEA) & Affairs (DEA) \\
\hline Geodesy & CChief & Chief \\
Dataset & Directorate & Directorate \\
& National & National \\
& Geospatial & Geospatial \\
& Information & Information \\
& (CD: NGI & (CD: NGI \\
\hline
\end{tabular}

Table 6.1 Identified data custodians

\section{Results}

Raw data was collected from identified data custodians by means of a Questionnaire on Data Sharing of Geospatial Data and five interviews with the experts from other countries and the Director of NSIF around geospatial data sharing and spatial data infrastructure implementation and legislation around geospatial data sharing. Tables and summary techniques were used to represent the raw data.

Ten (10) data custodians were identified and from this seven (7) responded via email to the data custodian sharing questionnaire. 
Table 1: Identified data custodian responses

\subsection{Knowledge of Spatial Data Infrastructure Act,} 2003

This measures the knowledge of the SDI Act of 2003, the existence of the Committee for Spatial information (CSI) and the level of the familiarity of the CSI activities.

\subsection{Supplying/ sharing of geospatial data}

This section of the research is presenting the data sets that are shared/supplied by the identified data custodians and if they also supply other datasets that are not part of the identified data themes, as identified by the CSI. This section also covers if metadata is available for the datasets.

\subsection{Compliance to SDI Act, 2003}

The shows the compliance to the SDI Act by the identified data custodians in the areas of metadata, documented procedures, memorandum of agreement with users, reporting or errors, standards, approved policies, duplication of data acquisition, file formats, and consultation on user needs.

\subsection{Restrictions in sharing/suppling geospatial data}

This section shows copyright, legal conditions and other restrictions of sharing of geospatial data of the identified data custodian that responded. The other restrictions can be linked to security or protection reasons relating to sharing of geospatial data.

7.5 Capacity and capability and issues for sharing/supplying geospatial data

This section discusses the capacity in terms of employees required and if they are adequately skilled. It also looks at the current budget and if it is sufficient to supply/share geospatial data, and looks at co-funding arrangements with other organisations. It looks at the IT infrastructure and assesses if the infrastructure is adequate, and also looks at other limitations that can hinder the supply/ sharing of geospatial data. This section also gives the identified data custodian the opportunity to raise other issues relating to the supply/ sharing of geospatial data.

\subsection{Interviews with other countries}

Five interviews were completed with leading international representatives from four (4) countries.

\begin{tabular}{|l|}
\hline Organisation \\
\hline United States of America (USA) \\
\hline Indonesia \\
\hline Belgium \\
\hline Director of NSIF) \\
\hline
\end{tabular}

USA,

Algeria, Indonesi a and Belgium were intervie wed to establish their legislatio regardin g spatial

\begin{tabular}{|c|c|c|}
\hline Organisation & Yes & No \\
\hline CD: NGI & $x$ & \\
\hline SANSA & $x$ & \\
\hline DEA & $x$ & \\
\hline SANRAL & & $x$ \\
\hline STATSSA & $x$ & \\
\hline CSG & $x$ & \\
\hline MDB & & $x$ \\
\hline Organisation & Yes & No \\
\hline doj \& cd & & $x$ \\
\hline SAGNC & $x$ & \\
\hline DWAS & $x$ & \\
\hline
\end{tabular}

\section{Discussion}

\subsection{Knowledge of SDI Act, 2003 and CSI Activities}

The results clearly shows that the majority of the identified data custodians have knowledge of the SDI Act and a high level of familiarity with the CSI activities, with six out of seven having a rating of 4 and more.

\subsection{Geospatial data sharing communication model}

From the literature it is important to learn that an effective geospatial data sharing communication model must be in place to ensure that geospatial data is accessible, available and usable to all relevant stakeholders. It is important to note that an effective SDI are better managed in a formal environment that tends to be supported by legislation, standards, guidelines and policies specific for SDI environment.

\subsection{Compliance with SDI Act, 2003}

An assessment of the current level of compliance with the SDI Act by the identified data custodians is made. The different dimensions of this assessment include metadata, documented procedures, memorandum of agreement with users, reporting of errors, standards, approved policies, duplication of data acquisition, and consultation on user needs, which are all responsibilities of the data custodians. 


\subsection{Restrictions on sharing of geospatial data}

From the analysis of the responses it shows that copyright restrictions on geospatial data of the identified data custodians is a common restriction, with 5 of the 7 responses showing copyright restriction exist. While only 2 of the 7 responses show that other legal restrictions exist. Of these, Stats SA indicate that their geospatial data may not be used for commercial purposes, and SANSA indicate that they do not own the data and so the end-user must comply with end-user licencing conditions and agreements.

Only 2 of the 7 responses indicate that they have restrictions based on security or protection reasons. Stats SA indicate that, in terms of legislation, they are required to protect the confidentiality of the person (human rights).

\subsection{Challenges with geospatial data sharing}

Data custodians may be willing to share their geospatial data and have a culture of sharing data but could be experiencing various challenges in doing so. These challenges could include issues of capacity (human, financial, and systems), and capability. An understanding of these challenges will go a long way to improving any current short- comings or 'forced' non-compliance with geospatial data sharing.

Any limitations to the various areas of geospatial data accessibility will negatively affect the sharing of geospatial data, including lack of awareness or knowledge on where to find geospatial data, buy-in from politicians and senior management., and lack of communication between data custodians and data recipients (users)

Comparative analysis with other countries

From the comparison with the four countries it is deduced that the South African approach is in line with the international best practice and that the SDI Act (Act No. 54 of 2003) is not too onerous for compliance with the requirements of the Act and related policies by data custodians.

\section{Conclusions}

Data custodians in South Africa have good knowledge of the Spatial Data Infrastructure Act (Act No. 54 of 2003) and of the existence of the Committee for Spatial Information (CSI), and are familiar with the activities of the CSI. Although this is the basis upon which the data custodians can comply with their responsibilities in terms of the SDI Act, there are challenges in geospatial data sharing in South Africa.

The reasons for these challenges are a lack of a good culture of geospatial data sharing, the metadata of available geospatial data not being submitted to the Electronic Metadata Catalogue resulting in the geospatial data not being discoverable, the lack of or inadequate communication between data custodian and the user, capacity and capability limitations on the side of the data custodian, the user and the National Spatial Information Framework, as the administrator for the South African Spatial Data Infrastructure (SASDI), limited bandwidth for geospatial data transfer, and lack of buy-in from the political and senior management level for implementing SASDI.

The identified data custodians in this research partially comply with the requirements of the SDI Act in terms of geospatial data sharing. The main area of non-compliance is with the submission of the metadata to the Electronic Metadata Catalogue (EMC) and the maintenance of those metadata records.

This results in the available geospatial data not being discoverable by the user and the duplication of the collection of geospatial data. There is also a level of noncompliance with regard to the requirement to report errors and inconsistencies in the geospatial data. The data custodians can also improve on the communication with users.

Based on the comparison with other countries it is concluded that the South African legislation (SDI Act and policies) is on a par with international best practice and as such the requirements of the legislation are not too onerous for the data custodians to comply with for geospatial data sharing. There could be improvements to the SDI Act to ensure improved compliance. It is noted that a national spatial data infrastructure, such as SASDI, need many years to be successfully implemented. During this time there must be support to and knowledge building for the data custodians.

\section{Recommendations}

\section{Recommendation 1:}

Measures should be put in place to address the current challenges being experienced with respect to geospatial data sharing. These measures should include, among others:

- Support to the data custodians to submit and manage the metadata on the Electronic Metadata Catalogue;

- Improved communication between data custodians, the users and other role-players, using the geospatial data sharing communication model in the context of a good culture for geospatial data sharing;

- Adequate capacity (human and financial) for the National Spatial Information Framework, as the administrator for SASDI, including the most appropriate placement of this function within government);

- Activities to advance the awareness of SASDI, policies, the CSI, standards and the societal benefits of geospatial data;

- Improved data communication infrastructure (bandwidth) that is affordable.

\section{Recommendation 2:}

Amend the Spatial Infrastructure Act to include measures to improve the implementation of SASDI, compliance with requirements of the Act and policies, and the governance thereof.

Further research recommendations: 
Recommendation 3:

Research improved mechanisms for the sharing of geospatial data, in particular the automation of access to and supply of geospatial data, to reduce the effort level on both the data custodian and the data recipient (user).

Recommendation 4:

Investigate the effectiveness of the geospatial data sharing communication model.

Recommendation 5:

Investigate the accessibility and availability of geospatial data to all relevant stakeholders.

Recommendation 6:

Investigate the effectiveness of standards for geospatial data sharing.

\section{References}

Chauke, M. 2016b. Interview with Director: National Spatial Information Framework, South Africa on 5 October 2016, Pretoria

Deloatch, I. 2016. Interview with Director: Federal Geographic Data Committee, USA on 25 May 2016, Rotterdam

Kardono, P. 2016. Interview with expert on 25 May 2016, Rotterdam

Omrane, N. 2016. Interview with expert on 25 May 2016, Rotterdam

Republic of South Africa. 2004. Spatial Data Infrastructure Act, 2003 (Act no. 54 of 2003)

Van den Berghe, I. 2016. Interview with DirectorGeneral: IGN, Belgium on 25 May 2016, Rotterdam 